\title{
LITERATURA INFANTIL E EDUCAÇÃO FÍSICA: PENSANDO NA EDUCAÇÃO INFANTIL
}

\author{
LITERATURA INFANTIL Y EDUCACIÓN FÍSICA: PENSANDO EN LA EDUCACIÓN \\ INFANTIL
}

\author{
CHILD LITERATURE AND PHYSICAL EDUCATION: THINKING ABOUT CHILD \\ EDUCATION
}

\author{
Karine da Silva WASUM ${ }^{1}$ \\ Viviane Maciel Machado MAURENTE²
}

RESUMO: O presente artigo é um estado da arte com sua revisão sistemática. Sendo este qualitativo através da revisão bibliográfica originada na busca de dados nos bancos BDTD e CAPES. O objetivo é tecer considerações a partir das pesquisas encontradas referentes ao uso de histórias infantis nas aulas de movimento na Educação Infantil, buscando realizar uma interlocução com as publicações que mais se aproximam deste tema. Diante dos resultados encontrados constatou-se quatro apontamentos: nenhum trabalho específico sobre o tema buscado; os trabalhos encontrados com o tema literatura infantil como meio para ensinar algum assunto específico não eram na totalidade sobre Educação Infantil; quase todas as pesquisas apresentaram um capítulo ou subcapítulo sobre a história da literatura infantil e sua importância na Educação e; os principais autores que se destacaram entre elas foram Vygotsky e Zilberman.

PALAVRAS-CHAVE: Literatura infantil. Educação física. Educação infantil.

RESUMEN: Este artículo es un estado del arte con su revisión sistemática. Este al ser cualitativo a través de la revisión bibliográfica originada en la búsqueda de datos en las bases de datos BDTD y CAPES. El objetivo es hacer consideraciones a partir de las investigaciones encontradas sobre el uso de cuentos infantiles en las clases de movimiento en Educación Infantil buscando entablar un diálogo con las publicaciones más cercanas a esta temática. A la vista de los resultados encontrados, se encontraron cuatro notas: ningún trabajo especifico sobre el tema buscado; las obras encontradas con el tema de la literatura infantil como medio para enseñar una asignatura específica no fueron enteramente sobre Educación Infantil; casi todas las investigaciones presentaron un capítulo o subcapítulo sobre la historia de la literatura infantil y su importancia en Educación y; los principales autores que se destacaron entre ellos fueron Vygotsky y Zilberman.

\footnotetext{
${ }^{1}$ Universidade Estadual do Rio Grande do Sul (UERGS), Osório - RS - Brasil. Mestranda no Programa de PósGraduação em Mestrado Profissional em Educação. ORCID: https://orcid.org/0000-0003-1004-6371. E-mail: karinewasum@gmail.com

${ }^{2}$ Universidade Estadual do Rio Grande do Sul (UERGS), São Luiz Gonzaga - RS - Brasil. Professora Adjunta, atua no Programa de Pós-Graduação em Mestrado Profissional em Educação. Doutorado em Educação em Ciências: Química da Vida e Saúde (UFRGS). ORCID: https://orcid.org/0000-0002-3976-6594. E-mail: vivianemaurente@uergs.edu.br
}

RPGE- Revista on line de Política e Gestão Educacional, Araraquara, v. 25, n. 2, p. 1328-1345, maio/ago. 2021. e-ISSN: 1519-9029 DOI: https://doi.org/10.22633/rpge.v25i2.14912 
PALABRAS CLAVE: Literatura infantil. Educación física. Educación infantil.

ABSTRACT: This article is a state of the art with its systematic review. Being of qualitative nature through the bibliographic review originated in the search for data in the BDTD and CAPES databases. The objective is to make considerations based on the research found regarding the use of children's stories in movement classes in Early Childhood Education seeking to engage in a dialogue with the publications that are closest to this theme. In view of the results, four notes were found: no specific work on the topic sought; the works found on the subject of children's literature as a means to teach a specific subject were not entirely about Early Childhood Education; almost all the researches presented a chapter or subchapter about the history of children's literature and its importance in Education and; the main authors who stood out among them were Vygotsky and Zilberman.

KEYWORDS: Children's literature. Physical education. Child education.

\section{Introdução}

Dois mil e vinte e um, ano corrente, ainda se percebe que a Educação Física se mantém na luta para obter um lugar estável e reconhecido no meio da educação. Desde seu surgimento, depara-se com constantes questionamentos de seu papel na vida dos estudantes sendo necessário uma repetição de afirmações e aprovações da sua importância. Não seria diferente na Educação Infantil. Professoras sem formação específica de Educação Física encontram-se com a obrigação de trabalhar a cultura do movimento humano a partir do pouco que aprenderam em sua graduação em Pedagogia ou Curso Normal de Nível Médio. Em alguns casos, nas escolas que atendem Ensino Fundamental e Educação Infantil, com Faixa Etária de quatro e cinco anos, é reservado para as turmas um único período semanal para desenvolver o corpo com professor formado em Educação Física. Mas o que é a Educação Infantil se não o corpo? Inclusive, na Base Nacional Comum Curricular, entre os cinco campos de experiências, há o denominado corpo, gestos e movimentos que traz o corpo como algo central da criança na Educação Infantil:

Na Educação Infantil, o corpo das crianças ganha centralidade, pois ele é o partícipe privilegiado das práticas pedagógicas de cuidado físico, orientadas para a emancipação e a liberdade, e não para a submissão. Assim, a instituição escolar precisa promover oportunidades ricas para que as crianças possam, sempre animadas pelo espírito lúdico e na interação com seus pares, explorar e vivenciar um amplo repertório de movimentos, gestos, olhares, sons e mímicas com o corpo, para descobrir variados modos de ocupação e uso do espaço com o corpo (tais como sentar com apoio, rastejar, engatinhar, escorregar, caminhar apoiando-se em berços, mesas e cordas, saltar, escalar, equilibrar-se, correr, dar cambalhotas, alongar-se etc.) (BRASIL, 2017, p. 41, grifo nosso) 
Partindo disto, o corpo como um dos principais objetivos da etapa da educação básica Educação Infantil, destaco outro ponto de suma importância: a forma como são abordadas as aulas de Educação Física. Isso porque, é de suma relevância uma aula que atinja o maior número possível de crianças da turma e que colabore com o desenvolvimento dessa faixa etária. No desenrolar de minha carreira profissional enquanto professora titular de turma da Educação Infantil estou a observar, ano após ano, a necessidade essencial de estimular o desenvolvimento corporal das crianças para que consigam acompanhar as demais aprendizagens esperadas nesta etapa. Recebemos, e cito no plural pois observo não somente a minha turma, mas as demais da escola, meninos e meninas que apresentam diferentes estágios de suas habilidades motoras. Sendo que muitos, em estágios anteriores ao esperado para sua idade. Logo, me estimula a refletir sobre como apresentar e desenvolver estratégias que estimulem as crianças a desenvolverem sua visão e compreensão de seu corpo de forma natural criando sentido para elas.

Neste ano, além de ser titular de uma turma de faixa etária de 5 anos, estou a entrar no turno contrário em turmas de 4 e 5 anos nos dias de planejamento dos professores titulares com o projeto "Mediação a Leitura". Ao elaborar os planejamentos envolvendo a literatura infantil, optei em desafiar-me para que semanalmente apresentasse uma história infantil às crianças e que desta partissem brincadeiras, jogos e atividades. Prontamente em consonância com o que a BNCC (BRASIL, 2017) traz, já citado anteriormente. Afinal, a Base Nacional Comum Curricular em especial o campo de experiências "corpo, gestos e movimentos" enfatiza que o corpo deve ser estimulado através de oportunidades com espírito lúdico. E a ludicidade iniciará já no momento da hora do conto com as histórias infantis selecionadas. Com tudo isso, questiono-me quais seriam as publicações referentes a utilização da literatura infantil nas aulas de Educação Física das crianças da Educação Infantil.

Para isso, realizei um estudo do conhecimento. Destaco que estudo do conhecimento ou também chamado de estado da arte, segundo Ferreira (2002), é uma forma de pesquisa que está se disseminando há uns 15 anos e visa encontrar diferentes publicações sobre o tema a ser investigado. Como ela mesmo diz:

são reconhecidas por realizarem uma metodologia de caráter inventariante e descritivo da produção acadêmica e científica sobre o tema que busca investigar, à luz de categorias e facetas que se caracterizam enquanto tais em cada trabalho e no conjunto deles, sob os quais o fenômeno passa a ser analisado (FERREIRA, 2002, p. 258). 
Inclusive, Morosini (2015) apresenta um estudo referente a estados da arte no Brasil, citando a persistência da área da Educação enquanto criação destes: "No Brasil, a consolidação da produção científica sobre Educação é ainda incipiente, identificando-se um crescente esforço desta área na construção de estados de conhecimento" (MOROSINI, 2015, p.102). Além disso, o estado da arte tem grande relevância para pesquisadores em suas dissertações e teses como, novamente, Morosini (2015, p. 114) destaca enquanto relata a importância enquanto inserção no campo científico e na área do objeto a ser pesquisado:

Uma destas possibilidades a despontar é a construção de estados de conhecimento, aqui entendidos como identificação, síntese e reflexão sobre o já produzido sobre uma temática em um determinado recorte temporal e espacial. Numa perspectiva de aprendizagem ativa e colaborativa, pela qual o sujeito assume o compromisso com a sua reflexão crítica, com a construção de seu objeto e com a inserção no campo científico.

Tendo consciência do que é e da relevância de um estudo da arte sobre o tema que trago em questão, realizei uma busca na Biblioteca Digital de Teses e Dissertações Brasileiras (BDTD) assim como também nas Teses e Dissertações da CAPES como forma de criar este estudo do conhecimento. Visando a ampliação de possibilidades de encontrar pesquisas com o tema apresentado foram usadas seis combinações de descritores: literatura infantil e práticas corporais, literatura infantil e brincadeiras, literatura infantil e jogos, literatura infantil e movimento, literatura infantil e corpo e literatura infantil e educação física. Essa busca teve como objetivo tecer considerações a partir das pesquisas encontradas referente ao uso de histórias infantis nas aulas de movimento na Educação Infantil buscando realizar uma interlocução com as publicações que mais se aproximam deste tema. Logo, sendo uma pesquisa bibliográfica e qualitativa, uma vez que há reflexão dos dados selecionados.

\section{Contribuições a partir da busca no Banco Digital de Teses e Dissertações Brasileiras (BDTD)}

Ao buscar pelo BDTD, utilizei os seis descritores já listados anteriormente em uma tentativa de ampliar o número de trabalhos com semelhança ao tema buscado. Também, não limitei espaço de tempo, pois os resultados seriam ainda menores do que os encontrados. Inicialmente, a partir da leitura do título e resumo das pesquisas, selecionei com o primeiro descritor quatro textos, com o segundo sete trabalhos, com o terceiro duas pesquisas, com o quarto uma publicação, com o quinto nenhum e finalmente com o sexto mais sete textos. Com isso, totalizando 21 trabalhos a partir dos títulos, apontando para um dos dois temas na 
Educação Infantil: Literatura Infantil ou Educação Física e demais sinônimos utilizados nos descritores. Ao verificar resumos e sumários acabei fazendo um novo refinamento, pois alguns trabalhos não abordavam de forma principal os temas em aqui em foco. Com isso, o resultado foi de cinco trabalhos que apresentavam capítulos discorrendo sobre os assuntos buscados. Também, estes cinco trabalhos apresentam a leitura infantil como colaboradora no trabalho interdisciplinar com áreas como matemática, letramento, moralidade e gênero. Buscando uma melhor visualização do leitor, apresento, no quadro 1, os dados das pesquisas analisadas.

Quadro 1 - Trabalhos selecionados a partir dos 6 descritores que utilizam a literatura infantil como ferramenta de ensino de determinados temas

\begin{tabular}{|c|c|c|}
\hline Ano & Título & Autor \\
\hline 2005 & Dialogando com crianças sobre gênero através da literatura infantil & $\begin{array}{l}\text { Zandra Elisa } \\
\text { Argüello }\end{array}$ \\
\hline 2006 & $\begin{array}{l}\text { Matemática e literatura infantil: sobre os limites e possibilidades de um desenho } \\
\text { curricular interdisciplinar }\end{array}$ & $\begin{array}{l}\text { Adriano Edo } \\
\text { Neuenfeldt }\end{array}$ \\
\hline 2007 & $\begin{array}{l}\text { Literatura e imaginação: realidade e possibilidades em um contexto de educação } \\
\text { infantil }\end{array}$ & Taís Danna \\
\hline 2010 & $\begin{array}{l}\text { A literatura infantil e a matemática: um estudo com alunos de } 5 \text { e } 6 \text { anos de idade } \\
\text { da educação infantil }\end{array}$ & $\begin{array}{l}\text { Regiane Perea } \\
\text { Carvalho }\end{array}$ \\
\hline 2018 & $\begin{array}{l}\text { Atividades de letramento na Educação Infantil: o trabalho com a literatura como } \\
\text { elo entre as modalidades oral e escrita }\end{array}$ & Ariane Ranzani \\
\hline
\end{tabular}

Fonte: Elaborado pelas autoras

De modo geral, as dissertações e teses trazem em seu desenrolar apontamentos em comum sobre a Literatura Infantil assim como a Educação Infantil, porém com exploração dos contos de forma diferente. Destaco que estes seis são das áreas de Linguística, Psicologia, Matemática e Educação.

Trago agora, uma análise mais minuciosa dos trabalhos visando descrever as partes que se relacionam com a literatura infantil e a Educação Física. Como Ferreira (2002, p. 270) fala, essas buscas são como uma "rede de vários fios que se cruzam, que se rompem, que se unem, que se questionam dependendo do ponto que se estabelece como partida em cada texto".

Início a análise com a tese denominada Atividades de letramento na Educação Infantil: o trabalho com a literatura como elo entre as modalidades oral e escrita. A autora é Ariane 
Ranzani com defesa de sua tese em 2018. Realizou o trabalho pelo Programa de PósGraduação em Linguística da Universidade Federal de São Carlos.

Ranzani (2018) apresenta inicialmente em seu trabalho a dúvida dos profissionais da Educação Infantil enquanto utilizar a linguagem nas modalidades oral e escrita principalmente referente ao mundo letrado. Também enfatiza sobre as diferentes metodologias possíveis para as aulas de Educação Infantil. Com isso, ela apresenta sua pesquisa onde desenvolveu um trabalho pedagógico com as crianças da etapa 6 da Educação Infantil. Nesse seu trabalho, a partir da leitura de livros de literatura infantil ela aborda com consistência a modalidade escrita da linguagem. Destaco de seu trabalho vários momentos. Um deles, o subtítulo de sua introdução denominado de "A leitura e a escrita na Educação Infantil” onde ela traz as autoras Brandão e Leal (2011) para abordar a história referente a utilização da leitura até os anos 1960. De acordo com a fala delas, a leitura infantil deveria ser evitada até os 6 ou 7 anos etapa que denominados de Educação Infantil atualmente. Ranzani também continua a reflexão em cima das pesquisadoras refletindo que a partir dos anos 1970 e 1980 surgem novas vertentes de pensamentos colocando em dúvida esse receio da utilização da leitura o que segue até hoje em forma de dúvida entre alfabetizar ou não na Educação Infantil.

Seguindo, ela traz no Capítulo 1 um subtítulo denominado "Atividades letradas: os gêneros do discurso e a literatura infantill". Nele a autora aborda um letramento que ultrapassa a modalidade escrita. Justifica essa fala trazendo o autor Kleiman (2009, p. 2, grifo nosso) que destaco aqui por vir de encontro ao meu tema de pesquisa:

[...] são consideradas atividades letradas aquelas que envolvem outros sistemas semióticos, como o gestual-corporal, ou a oralidade e, assim, são consideradas letradas aquelas atividades realizadas pela criança não alfabetizada folheando e manuseando um livro ou escutando a leitura de um conto infantil; ou pelo adulto escutando um programa de rádio ou assistindo a uma palestra. Até o próprio estilo de fala de pessoas que leem e escrevem muito e que, por isso, adquirem traços e características próprias da tessitura da escrita é considerado um estilo letrado de falar, ou uma fala letrada.

Mantendo-se ainda neste capítulo, em outro subtítulo chamado "O livro de literatura infantil e a apropriação da linguagem" a autora inicia trazendo Mortatti (2014) para apresentar o processo de Educação Escolar. Para Mortatti segundo Ranzani (2018) este processo tem três sentidos que se completam sendo eles: a educação da literatura, a educação pela literatura e a educação para literatura. O segundo, educação pela literatura, teria como mediadora a leitura para o desenvolvimento do ensino. Logo, sentido pelo qual meu tema se situa, pois, a ideia é 
utilizar a Literatura Infantil como mediadora da ludicidade para o trabalho com o Movimento.

Já no subtítulo “A atividade da criança” Ranzani apresenta Vigotski (2007) e Leontiev (2014) abordando sobre a brincadeira para as crianças da Educação Infantil. A pesquisadora escreve, a partir destes dois autores supracitados, que a brincadeira não ocorre buscando um resultado final, e que a motivação já é o processo da mesma.

Por fim, destaco a conclusão apresentada no resumo da Ranzani que aborda novamente a brincadeira com ligação a leitura infantil:

\begin{abstract}
Desse modo, os resultados destacam a pertinência das atividades de tradução literária no sentido de proporcionar a travessia da criança pelos mais variados gêneros discursivos, estabelecendo elos entre as modalidades oral e escrita da linguagem; por considerar a brincadeira como atividade principal no desenvolvimento afetivo-cognitivo que possibilita a atividade de tradução literária da criança; e, ainda, por possibilitar que a criança adentre o mundo da linguagem de forma subjetiva e criativa, transformando-a e transformando-se (RANZANI, 2018, p.8, grifo nosso).
\end{abstract}

A partir desses comentários e trechos aqui mencionados, Ranzoni aborda pontos em sua pesquisa que se relacionam com o tema proposto. Os quais são: a utilização da leitura no decorrer dos anos, bem como o processo de escrita. Também, destaca as possíveis formas de utilização da leitura infantil onde a educação pela leitura se encaixa em meu tema. Além, destaca a brincadeira na Educação Infantil e a comunicação dela com a literatura infantil.

O segundo trabalho é uma dissertação pelo Programa de Pós-Graduação em Psicologia da Universidade Federal de Santa Catarina. Tem como título Literatura e Imaginação: Realidade e possibilidades em um contexto de Educação Infantil. Sua defesa ocorreu em 2007.

Já no resumo e apresentação, nota-se que a autora Danna (2007) teve inspiração em sua vivência com a leitura durante os momentos de sua vida. A partir disto, buscou saber como era o espaço e valor dado para a literatura infantil na Educação Infantil.

A autora apresenta antes do capítulo 1 uma parte denominada de "Literatura: algumas definições”. Neste Danna faz uma breve escrita da evolução: palavra, texto, livro, literatura até chegar na literatura infantil. No mesmo capítulo ela já delimita o seu campo de pesquisa e apresenta seu estado da arte. Nele, ela utilizou assim como na pesquisa anterior Vygotski, nesse caso como descritor para pesquisa buscando a perspectiva do materialismo histórico.

No capítulo 1, ela traz discussões sobre infância, literatura e imaginação. Sobre infância, Danna traz Ariès (1981) como embasamento para falar sobre a história da infância e 
as influências para essas concepções no decorrer do tempo. Ao abordar sobre o espaço da Educação Infantil, a autora traz a legislação Lei de Diretrizes e Bases da Educação Nacional de 1996 (LDB) para justificar que apenas neste momento, a Educação Infantil passa a receber um olhar digno. Num terceiro momento, ainda do capítulo 1, Danna enfatiza a literatura infantil e o conceito de imaginação criativa em Vygotski trazendo uma maior discussão e material que se assemelha ao meu tema de pesquisa.

Ao falar sobre o surgimento da literatura infantil é apresentado Zilberman (1984) o qual a pesquisadora parafraseia contando que foi a partir do século XVIII que se passou a pensar em literatura infantil a partir da ascensão da burguesia e a nova forma de se pensar infância. Também, enfatiza que inicialmente os livros infantis eram utilizados como meios de trabalhar princípios morais. No decorrer da escrita, Danna também faz menção ao brincar na infância tendo André (2000) como suporte teórico. Ela cita que o brincar é imprescindível pois é a partir dele que ocorrem aprendizagens desde a criança pequena.

Nos demais capítulos a pesquisadora explica sua metodologia e conta sua prática investigativa referente ao uso da literatura infantil e os espaços utilizados para isto. No decorrer do texto, Danna apresenta Barcellos e Neves (1995) onde ela parafraseia que a história nem sempre vem no livro pronta para abordar com as crianças e que a forma do narrador contar e o espaço e demais ações completam a compreensão tornando mais ativo e dinâmico o momento. Outro autor utilizado foi Abramovich (1997) para completar a necessidade de o narrador da história ter a lido antes para passar domínio e confiança para as crianças durante a contação.

Durante a conclusão, Danna refere-se a dois tipos de momentos de leitura sendo narrativa com livro conceituada, a partir de Barcellos e Neves (1995) parafraseado pela autora como um momento com o livro segurado pela narradora sendo folheado com o intuito das crianças verem as imagens e o contador da história já sabendo a narrativa. E o segundo é narrativa livre onde ela denomina de: "é aquela na qual não se utiliza o apoio do livro, apresentando maior abertura para expressão e interação lúdica, por ser mais flexível e independente do texto escrito" (DANNA, 2007, p. 132-133).

Deste segundo trabalho as aproximações com o tema buscado foram a Educação Infantil onde ela traz uma breve escrita sobre a história e legislação. Também, a literatura infantil enquanto localização no tempo assim como as duas formas de leitura das histórias. Em alguns momentos, falando de imaginação e criação, Danna enfatiza o brincar como essencial aproximando-se também de minha pesquisa. 
Com "A literatura infantil e a matemática: um estudo com alunos de cinco e seis anos da Educação Infantil" começo a terceira busca por assuntos em comum. Esse trabalho é uma dissertação do Mestrado profissional em Ensino de Matemática da Pontifícia Universidade Católica de São Paulo defendido no ano de 2010.

Já no resumo identifico um fator em comum entre as três escritas comentadas até o momento: Vygotski. Neste trabalho escrito por Carvalho (2010) ela também utiliza este autor como embasamento teórico.

A autora já envolve no problema da pesquisa o uso da literatura infantil para o ensino da matemática utilizando movimentos corporais. Com isso, abordando os dois assuntos principais que busco.

No capítulo 2 a autora se detém na relação histórica da Educação Infantil. Nos demais aborda a teoria de Vygotsky o qual utiliza de forma consistente no decorrer do trabalho relatando sua ação com as crianças.

$\mathrm{Na}$ conclusão, relata sobre o brincar na perspectiva Vygotskiana destacando o favorecimento de situações de criação imaginária envolvendo também situações já vividas. Destaco a citação: “As crianças ao brincar, jogar, imitar, criar ritmos e movimentos também se apropriam do repertório da cultura corporal na qual estão inseridas" (CARVALHO, 2010, p. 103).

Apesar de inicialmente abordar os movimentos corporais, de fato a maior ênfase deste trabalho e ação realizada foi com intuito da aprendizagem matemática. Com isso, o momento de maior aproximação com meu trabalho se torna o momento de escrita referente a história da Educação Infantil.

O quarto trabalho tem como título Matemática e literatura infantil: sobre os limites e possibilidades de um desenho curricular interdisciplinar. É uma dissertação do mestrado da Universidade Federal de Santa Maria do Programa de Pós-Graduação em Educação. Foi defendida em 2006.

Neuenfeldt (2006), a autora, inicia seu trabalho trazendo conceitos teóricos em seu primeiro capítulo. Destaco o termo interdisciplinaridade onde entre os autores abordados estão Lück que cita o conceito deste termo como visão conjunta das diversidades de forma que faça sentido:

Busca-se estabelecer o sentido de unidade na diversidade, mediante uma visão de conjunto que permita ao homem fazer sentido dos conhecimentos e informações dissociados e até mesmo antagônicos que vem recebendo, de tal modo que possa reencontrar a identidade do saber na multiplicidade de conhecimentos (LÜCK, 1994, p. 59). 
Como a pesquisa apresentava este objetivo curricular interdisciplinar, foi utilizada a literatura infantil como eixo balizador. Com isso apresenta um subcapítulo dedicado a conceito, história e aplicação da literatura infantil na escola. Os autores utilizados foram: Coelho (2000), Magalhães (1984), Carvalho (1987), Abramovich (1997), Smole (2000) e Amarilha (2002). Dou ênfase aos autores deste assunto visando que a literatura também se fará presente em minha pesquisa.

Como teorias, Neuenfeldt (2006) também apresenta Vygotsky $(1988 ; 1994 ; 1998)$ envolvendo a aprendizagem em um ambiente histórico e cultural e Freire (1983 e 2000) enquanto dialogicidade. Em resumo, nesta pesquisa, interdisciplinaridade e literatura infantil se enquadram ao tema da pesquisa.

$\mathrm{Na}$ continuidade falarei sobre a pesquisa "Dialogando com crianças sobre gênero através da literatura infantil". É uma dissertação de mestrado em Educação pela Universidade Federal do Rio Grande do Sul defendida em 2005.

Inicialmente destaco, perceptível já no resumo, que a autora Argüello (2005) diferentemente dos demais trabalhos analisados até aqui, apresenta como teórico Michel Foucault. Como material de análise a autora a partir de histórias infantis que abordam gênero analisou as falas das crianças durante a conversação da hora do conto. No decorrer da dissertação, o momento que se aproxima de meu tema é no capítulo três onde a Argüello (2005) escreve sobre a literatura infantil no subcapítulo 3.3. Entre os autores, ela apresenta Coelho (2000) e a definição de literatura infantil com vínculo ao pedagógico: "é também ela necessariamente pedagógica, no sentido amplo do termo, e assim permanece mesmo no caso em que ela se define como literatura de puro entretenimento [...]" (COELHO, 2000, p. 31). Nos demais momentos de escrita, Argüello (2005) não disserta sobre assuntos referentes ao meu objeto de pesquisa.

Terminada esta etapa, parto para a análise do segundo banco de dados que teço logo abaixo.

\section{Contribuições a partir da busca no banco de teses e dissertações da Coordenação de Aperfeiçoamento de Pessoal de Nível Superior (CAPES)}

Quadro 2 - Trabalhos selecionados a partir dos 6 descritores que utilizam a literatura infantil como ferramenta de ensino de determinados temas

\begin{tabular}{|c|c|c|}
\hline Ano & Título & Autor \\
\hline 2013 & A literatura infantil e a formação humanística no cotidiano da sala de & Viviane Sulpino da Silva \\
\hline
\end{tabular}




\begin{tabular}{|c|c|c|}
\hline & aula & \\
\hline 2016 & $\begin{array}{l}\text { A literatura infantil e o discurso da Educação Ambiental escolarizada: } \\
\text { lições de como cuidar do planeta }\end{array}$ & Camila da Silva Magalhães \\
\hline 2018 & $\begin{array}{l}\text { A literatura infantil e a formação cidadã: } O \text { fazer docente na } \\
\text { Educação Infantil }\end{array}$ & $\begin{array}{l}\text { Kelly Cristina Vaz de } \\
\text { Carvalho Marques }\end{array}$ \\
\hline 2018 & $\begin{array}{l}\text { A mediação do livro ilustrado de literatura infantil: ver, pensar e fazer } \\
\text { artes visuais na escola }\end{array}$ & Estrela Pereira dos Santos \\
\hline
\end{tabular}

Fonte: Elaborado pelas autoras

Para chegar nestes trabalhos, foi utilizado como critério de busca os mesmos seis descritores já citados anteriormente. Com eles, inicialmente foram encontrados o total de 12 trabalhos relacionados a literatura infantil levando em consideração os títulos. Porém, após leitura mais minuciosa dos resumos, sumários e introdução, os trabalhos que envolvem a literatura para o meio de ensino de algo se resumiu em apenas quatro os quais foram listados na tabela logo acima.

De modo geral estas dissertações apontam, referente ao tema buscado, sobre a história da Literatura Infantil e importância dela. Também, alguns pontos referentes a imaginação. As pesquisas são das áreas de Educação, Educação Ambiental e Formação de Professores.

Assim como no subtítulo anterior, descrevo abaixo uma análise com maior detalhamento no intuito de encontrar pontos em comum com o tema buscado.

O primeiro trabalho tem como título "A mediação do livro ilustrado de literatura infantil: ver, pensar e fazer artes visuais na escola". É uma dissertação pelo programa de Educação da Universidade Federal do Rio Grande do Norte defendida em 2018.

Santos (2018), a autora, a partir de livros infantis explora as ilustrações para desenvolver conceitos referente a artes visuais com crianças de primeiro ano. O momento de maior identificação com meu tema é um subtítulo referente ao livro infantil e a ludicidade. Ela aponta alguns autores como Vygotsky que aborda diretamente sobre imaginação e traz suporte teórico para sua pesquisa:

a imaginação adquire uma função de suma importância na conduta e desenvolvimento humano, como forma de ampliar as experiências do homem, por ser ele capaz de imaginar o que não viu, baseando-se em relatos e descrições alheias de coisas que não experimentou pessoal ou diretamente, não está fechado no seu estreito círculo de suas próprias experiências [...] dessa forma, a imaginação constitui uma condição absolutamente necessária para quase toda função cerebral do ser humano (VYGOTSKY, 2003, p. 20). 
Assim como Santos (2018), a imaginação também estará presente em minha pesquisa, a partir do momento que a literatura infantil será mediadora desta.

Também, outro autor utilizado foi Oliveira (2005), que destaca o livro infantil como desencadeador da imaginação:

Os livros infantis, além de proporcionarem prazer, contribuem para o enriquecimento intelectual das crianças. Sendo esse gênero objeto da cultura, a criança tem um encontro significativo de suas histórias com o mundo imaginativo próprio. A criança tem a capacidade de colocar seus próprios significados nos textos que lê, isso quando o adulto permite e não impõe os seus próprios significados, visto estar em constante busca de uma utilidade que o cerca (OLIVEIRA, 2005, p. 125).

No desenrolar de seu trabalho a autora enfatiza Artes Visuais se destoando do tema buscado. Destaco a presença de Vygotsky no trabalho, o qual apareceu diversas vezes nas pesquisas do outro banco de dados.

O segundo trabalho é denominado "A literatura infantil e o discurso da Educação Ambiental escolarizada: lições de como cuidar do planeta". Uma dissertação na área de Educação Ambiental defendida em 2016.

Magalhães (2016), que escreveu a pesquisa acima, aborda em sua dissertação a análise de livros do Programa Nacional de Livros Didáticos e o discurso que eles traziam sobre Educação Ambiental. Aproxima-se do tema buscado no subtítulo "Situando a Trajetória da Literatura Infantil e sua Relação com a Escola”. Neste espaço de escrita ela utilizou autores como Zilberman e Magalhães (1987), Arroyo (1988), Coelho (1991), Oliveira (2007) entre outros para ir desenrolando a história da literatura infantil. No restante de sua escrita, ela dá ênfase para a educação ambiental fugindo do tema buscado.

O terceiro trabalho analisado "A literatura infantil e a formação humanística no cotidiano da sala de aula" se constitui como uma dissertação defendida em 2013 pelo Programa de Pós-Graduação em Formação de Professores. Em geral, a autora, Silva (2013) aborda no decorrer de sua dissertação sobre a Literatura Infantil enquanto história e importância, bem como visa enfatizar a estética. O primeiro e segundo capítulos, ambos conceituais, abordam na sequência: a literatura infantil no sentido amplo e após como uso pedagógico. Sendo assim, trazendo informações conceituais que vem de encontro ao tema proposto.

Interessante destacar que Silva (2013) parafraseia Cosson (2006, p. 47) para abordar os três tipos de aprendizagens envolvendo a literatura onde ela traz que: 
define a literatura como uma linguagem que compreende três tipos de aprendizagem: a aprendizagem da literatura, que consiste, fundamentalmente, em experienciar o mundo por meio da palavra; a aprendizagem sobre a literatura, que envolve conhecimentos de história, teoria e crítica, e a aprendizagem por meio da literatura. Nesse caso, os saberes e as habilidades que a prática da literatura proporciona aos seus usuários.

Com isso, abordando entre elas a possibilidade, a partir desta fala, de justificar também o uso da literatura infantil como mediadora da ludicidade nas aulas de movimento na Educação Infantil.

Outro autor que foi bastante recorrente nesta pesquisa foi Zilberman (1984) para referenciar conceito de Literatura Infantil. Aparecendo, também, em pesquisas anteriores aqui citadas.

A partir da intervenção na escola a autora pode perceber o uso da literatura como prazer e letramento/alfabetização. Reiterou durante seu trabalho de campo e nas conclusões finais que há necessidade de explorar mais as literaturas infantis como forma de compreender o papel cultural, social, ideológico, histórico e político delas.

$\mathrm{Na}$ quarta pesquisa, a qual recebeu o título de "A literatura infantil e a formação cidadã: O fazer docente na Educação Infantil”, temos como autora Marques, que defendeu sua dissertação em 2018 pelo Programa de Pós-Graduação em Educação.

De antemão na leitura do resumo identifiquei um trecho referente a imaginação, lúdico e literatura o qual enquadra-se ao que busco, na qual a autora reflete:

[...] a Literatura Infantil mostra-se uma aliada ao exercício da imaginação e da fantasia, mais precisamente na Educação Infantil, onde, através dos contos, é possível proporcionar de maneira simbólica e lúdica aspectos formativos que contribuem para o desenvolvimento físico, social e psicológico; sendo essencial nessa etapa de formação a presença do educador como intermediário do processo educativo (MARQUES, 2018, p. 9).

Já durante a introdução, Zilberman (2013), assim como em outros trabalhos, foi citado para justificar a importância da literatura infantil e Vygotsky (1999) se fez presente, também, como em outras pesquisas, embasando que a criança se desenvolve a partir do meio em que vive.

Marques (2018) traz no capítulo 3 uma contextualização sobre infância e em seguida, no capítulo 4, aborda sobre a Literatura Infantil. Neste capítulo, possui um subtítulo para dissertar sobre a literatura infantil e suas funções. Com isso apresenta, entre os autores que 
utilizou, Frantz (2011) para discutir a ludicidade sob o viés da literatura infantil, explicando que:

\begin{abstract}
A literatura infantil é também ludismo, é fantasia, é questionamento, e dessa forma consegue ajudar a encontrar respostas para as inúmeras indagações do mundo infantil, enriquecendo no leitor a capacidade de percepção das coisas. Como podemos perceber, a criança e a literatura infantil compartilham das mesmas naturezas - ambas são lúdicas, mágicas e questionadoras - e essas afinidades fazem com que a literatura seja a mais poderosa aliada do professor e da criança pela vida afora, na busca da compreensão do mundo e do ser humano (FRANTZ, 2011, p. 28).
\end{abstract}

Nos demais momentos a autora aborda sobre seus relatos durante a pesquisa de campo e suas constatações fugindo do tema aqui pesquisado.

\title{
Considerações finais
}

Como fator inicial, se faz necessário frisar o fato de não se encontrar, mesmo utilizando seis descritores em dois bancos de dados, nenhuma pesquisa referente a literatura infantil e o movimento. Desta forma, demonstrando a importância e necessidade de se desenvolver um trabalho em nível de Dissertação discorrendo sobre este tema.

Outro apontamento, destaco o número pequeno de trabalhos encontrados sobre a Literatura Infantil como mediadora no ensino de determinado assunto. Inclusive, neste pequeno número de trabalhos aqui expostos, nem todos são referentes a Educação Infantil, etapa da Educação Básica envolvida, foco desta pesquisa.

Destaco, também, que em quase todas as pesquisas em dissertações e teses, houve um capítulo ou subcapítulo que discorriam sobre a história da literatura infantil e a importância de sua utilização na Educação. Acreditando, assim ser relevante trazer para esse estudo essa contextualização.

Como última, mas não menos importante percepção, notou-se a utilização em grande parte dos trabalhos de Vygotsky e Zilberman para embasamento de imaginação e literatura infantil. Ambos os autores se reportam ao tema a que se propõe, sendo o primeiro à brincadeira e imaginação e o segundo a Literatura Infantil e seu período histórico.

Finalizo este trabalho retomando a importância da realização de estudos da arte. Tanto para percepção das pesquisas que estão sendo desenvolvidas sobre o tema a ser pesquisado, como também para o auxílio que traz enquanto levantamento de referências. Pensando na área da Educação, este trabalho vem a referenciar e detalhar trabalhos de Literatura Infantil mostrando que há grande possibilidade de exploração deste tema e vindo a instigar novos 
pesquisadores que se identificam com esta temática. Afinal, a partir desta busca, foi possível perceber que o tema literatura infantil e movimento na Educação Infantil é uma temática carente de aprofundamento podendo ser pioneira em Curso de Pós-Graduação Stricto Sensu.

\section{REFERÊNCIAS}

ABRAMOVICH, F. Literatura infantil. Gostosuras e Bobices. São Paulo, SP: Scipione, 1997.

ABRAMOWICZ, M. Avaliando a avaliação da aprendizagem: um novo olhar. São Paulo, RJ: Cortez, 1997.

AMARILHA, M. Estão mortas as fadas? Literatura infantil e prática pedagógica. 4. ed. Petrópolis, RJ: Vozes, 1997.

ANDRÉ, M. I. N. O brincar na educação infantil. Revista do Conselho Regional de Psicologia, Florianópolis, ano IV, n. 39, set. 2000.

ARGÜELLO, Z. E. Dialogando com crianças sobre gênero através da literatura infantil. 2005. 195 f. Dissertação (Mestrado em Educação) - Universidade Federal do Rio Grande do Sul, Porto Alegre, 2005. Disponível em:

https://lume.ufrgs.br/bitstream/handle/10183/6961/000537801.pdf?sequence=1\&isAllowed=y . Acesso em: 28 abr. 2020.

ÁRIES, P. História social da criança e da família. Rio de Janeiro, RJ: Guanabara, 1981.

ARROYO, L. Literatura Infantil Brasileira. São Paulo, SP: Melhoramentos, 1988.

BARCELLOS, G. M. F.; NEVES, I. C. B. Hora do conto: da fantasia ao prazer de ler subsídios a sua realização em bibliotecas públicas e escolares. Porto Alegre, RS: Sagra, 1995.

BRANDÃO, A. C. P.; LEAL, T. F. Alfabetizar e letrar na Educação Infantil: o que isso significa? In: BRANDÃO, A. C. P.; ROSA, E. C. S. Ler e escrever na Educação Infantil: discutindo práticas pedagógicas. Belo Horizonte, MG: Autêntica Editora, 2011.

BRASIL. Lei n. 9.394/96, de 20 de dezembro de 1996. Lei de Diretrizes e Bases da Educação Nacional. Brasília, DF, 23 dez. 1996. Disponível em:

http://www.planalto.gov.br/ccivil_03/leis/19394.htm. Acesso em: 28 abr. 2020.

BRASIL. Ministério da Educação. Base nacional comum curricular (BNCC). Brasília, DF: MEC, 2017.

CARVALHO, B. V. A literatura infantil: visão histórica e crítica. 5. ed. São Paulo, SP: Global, 1987.

CARVALHO, R. P. A literatura infantil e a matemática: um estudo com alunos de 5 e 6 anos de idade da educação infantil. 2010. 117 f. Dissertação (Mestrado em Educação) Pontifícia Universidade Católica de São Paulo, São Paulo, 2010.

RPGE- Revista on line de Política e Gestão Educacional, Araraquara, v. 25, n. 2, p. 1328-1345, maio/ago. 2021. e-ISSN: 1519-9029 
COELHO, N. N. Panorama histórico da literatura infantil e juvenil. 4. ed. São Paulo, SP: Ática, 1991.

COELHO, N. N. Literatura infantil: teoria, análise, didática. 7. ed. São Paulo, SP: Moderna, 2000.

COSSON, R. Letramento literário: teoria e prática. São Paulo, SP: Contexto. 2006.

DANNA, T. Literatura e imaginação: realidade e possibilidades em um contexto de educação Infantil. 2007. 147 f. Dissertação (Mestrado) - Universidade Federal de Santa Catarina, Florianópolis, 2007. Disponível em:

https://repositorio.ufsc.br/xmlui/bitstream/handle/123456789/90653/243421.pdf?sequence=1 \&isAllowed=y. Acesso em: 20 abr. 2020.

FERREIRA, N. S. A. As pesquisas denominadas "Estado da Arte". Educação \& Sociedade, ano XXIII, n. 79, p. 257-272, ago. 2002. Disponível em:

http://www.scielo.br/pdf/es/v23n79/10857.pdf. Acesso em: 26 mar. 2020.

FRANTZ, M. H. Z. O ensino da literatura nas séries iniciais. 3. ed. Ijuí, RS: UNIJUÍ, 2001.

FREIRE, P. Pedagogia do oprimido. 12. ed. Rio de Janeiro, RJ: Paz e Terra, 1983.

FREIRE, P. Pedagogia da autonomia. Saberes necessários à prática educativa. São Paulo, SP: Paz e Terra, 2000.

KLEIMAN, A. B. Projetos de Letramento na Educação Infantil. Revista Caminhos em Linguística Aplicada, v. 1, n. 1, 2009. Disponível em: http://periodicos.unitau.br/ojs2.2/index.php/caminhoslinguistica/ article/viewFile/898/ 716. Acesso em: 09 abr. 2015.

LEONTIEV, A. N. Os princípios psicológicos da brincadeira pré-escolar. In: VYGOTSKY, L. S.; LURIA, A. R.; LEONTIEV, A. N. Linguagem, desenvolvimento e aprendizagem. São Paulo, SP: Ícone, 2014. p. 119-142.

LÜCK, H. Pedagogia interdisciplinar: fundamentos teórico-metodológicos. Petrópolis, RJ: Vozes, 1994.

MAGALHÃES, C. S. A literatura infantil e o discurso da educação ambiental escolarizada: lições de como cuidar do planeta. 2016. 115 f. Dissertação (Mestrado) Universidade Federal do Rio Grande, Rio Grande, 2016.

MAGALHÃES, L. C.; ZILBERMAN, R. Literatura infantil: autoritarismo e emancipação. 2. ed. São Paulo, SP: Ática, 1984.

MARQUES, K. C. V. C. A literatura infantil e a formação cidadã: o fazer docente da educação infantil. 2018. 165 f. Dissertação (Mestrado em Educação) - Universidade Católica de Brasília, Brasília, 2018.

MOROSINI, M. C. Estado de conhecimento e questões do campo científico. Educação (UFSM), Santa Maria, v. 40, n. 1, p. 101-116, dez. 2014. ISSN 1984-6444. Disponível em: https://periodicos.ufsm.br/reveducacao/article/view/15822. Acesso em: 27 mar. 2020. 
MORTATTI, M. R. L. Na história do ensino da literatura no Brasil: problemas e possibilidades para o século XXI. Educar em Revista, Curitiba (PR), n. 52, p. 23-43, abr./jun. 2014. Disponível em: http://www.scielo.br/pdf/er/n52/03.pdf. Acesso em: 18 set. 2015 .

OLIVEIRA, M. A. A Literatura para crianças e jovens no Brasil de ontem e de hoje: caminhos de ensino. 2007. Tese (Doutorado) - Faculdade de Educação, Universidade de São Paulo, São Paulo, 2007.

RANZANI, A. Atividades de letramento na educação infantil: o trabalho com a literatura como elo entre as modalidades oral e escrita. 2018. $255 \mathrm{f}$. Tese (Doutorado) - Universidade Federal de São Carlos, São Carlos, 2018. Disponível em: https://repositorio.ufscar.br/bitstream/handle/ufscar/11074/TESE\%20Ariane\%20Ranzani.pdf? sequence $=1 \&$ isAllowed $=y$. Acesso em: 20 abr. 2020 .

SANTOS, E. P. A mediação do livro ilustrado de literatura infantil: ver, pensar e fazer artes visuais na escola. 2019. 173 f. Dissertação (Mestrado) - Centro de Educação, Universidade Federal do Rio Grande do Norte, Natal, 2019. Disponível em: https://repositorio.ufrn.br/jspui/handle/123456789/27239. Acesso em: 24 maio 2020.

SILVA, V. S. A literatura infantil e a formação humanística no cotidiano da sala de aula. 2013. 144 f. Dissertação (Mestrado Profissional em Formação de Professores) - Cetro de Educação, Universidade Estadual da Paraíba, Campina Grande, 2013.

SMOLE, K. C. S. A matemática na educação infantil: a teoria das inteligências múltiplas na prática escolar. Porto alegre, RS: Artes médicas sul, 2000.

VYGOTSKY, L. S. Linguagem, desenvolvimento e aprendizagem. Trad. Maria da Penha Villalobos. São Paulo, SP: Ícone, USP, 1988. (Coleção Educação Crítica)

VYGOTSKY, L. S. A formação social da mente: o desenvolvimento dos processos psicológicos superiores. São Paulo, SP: Martins Fontes, 1994.

VYGOTSKY, L. S. El problema del desarrollo cultural del niño y otros textos inéditos. Buenos Aires, Argentina: Editorial Almagesto, 1998. (Colleción Inéditos)

VYGOTSKY, L. S. Imaginación y creación en la edad infantil. 2. ed. Ciudad de La Habana, Cuba: Pueblo y Educación,1999.

VYGOTSKY, L. S. Pensamento e linguagem. 4. ed. São Paulo, SP: Martins Fontes, 2003.

VYGOTSKY, L. S. A formação social da mente: o desenvolvimento dos processos psicológicos superiores. 7. ed. São Paulo, SP: Martins Fontes, 2007.

ZILBERMAN, R. Literatura infantil: autoritarismo e emancipação. 2. ed. São Paulo, SP: Ática, 1984.

ZILBERMAN, R.; MAGALHÃES, L. C. Literatura infantil: autoritarismo e emancipação. São Paulo, SP: Ática, 1987.

RPGE- Revista on line de Política e Gestão Educacional, Araraquara, v. 25, n. 2, p. 1328-1345, maio/ago. 2021. e-ISSN: 1519-9029 
ZILBERMAN, R. A literatura infantil na escola. 11. ed. rev. atual. e ampl. São Paulo, SP, 2003.

\section{Como referenciar este artigo}

WASUM, K. S.; MAURENTE, V. M. M. Literatura infantil e educação física: pensando na educação infantil. Revista on line de Política e Gestão Educacional, Araraquara, v. 25, n. 2, p. 1328-1345, maio/ago. 2021. e-ISSN:1519-9029. DOI: https://doi.org/10.22633/rpge.v25i2.14912

Submetido em: $20 / 03 / 2021$

Aprovado em: 06/05/2021

Publicado em: 01/08/2021 